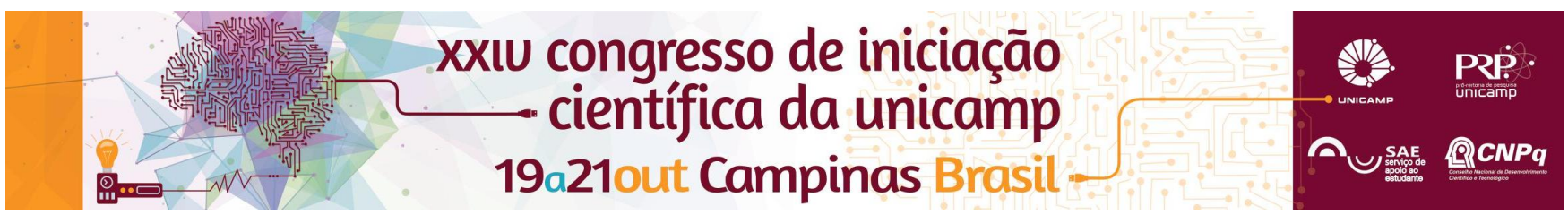

\title{
Internação compulsória de usuários problemáticos de substâncias: uma revisão (bibliográfica)
}

\section{Luís Fernando de Farah de Tófoli, Mayra Yumi Filipe*}

\section{Resumo}

No Brasil, há três tipos de internação: voluntária (que possui o consentimento do usuário), involuntária (que não possui o consentimento do usuário e é realizada por terceiros) e a compulsória (que é determinada pela Justiça)(1). Justificase a existência da internação compulsória pelo interesse da sociedade, interesse na saúde do paciente e motivos de autonomia(2). No entanto, a eficácia desse tipo de internação encontra obstáculos que podem violar os princípios da Bioética e dos Direitos Humanos. A partir da análise da literatura referente a esse tema, tanto de artigos nacionais como internacionais, foi realizada uma revisão narrativa, visto sua importância no quadro nacional, tanto socialmente quanto em relação à saúde pública.

\section{Palavras-chave:}

internação compulsória, Direitos Humanos, dependente químico

\section{Introdução}

A justificativa da internação compulsória ser necessária é composta por três principais razões: interesse da sociedade (pessoas com transtornos mentais podem ser perigosas com a própria família e com os cidadãos), interesse na saúde do paciente (caso ele seja uma ameaça para si mesmo e possa sofrer danos mentais ou físicos) e motivos de autonomia (quando o paciente perde a capacidade de autonomia e se torna tão doente que não consente com o tratamento necessário) ${ }^{(2)}$. Uma vez que o indivíduo dependente químico pode ser obrigado à internação por meio de ação judicial, coloca-se em dúvida se os princípios da bioética (não maleficência, beneficência, respeito à autonomia e justiça) estão sendo aplicados de forma adequada nesse caso $^{(3)}$. Diversas observações contestam a adequação da internação compulsória quanto aos Direitos Humanos como: falta de profissionais de saúde e tratamento terapêutico, práticas de tortura e castigo físico (como chantagens de não fornecer comida ao paciente), exposição a situações humilhantes, obrigação de realizar exames anti-HIV (a obrigatoriedade é ilegal), contenções mecânicas e medicamentosas ${ }^{(4,5)}$. Devido às divergências em relação à internação compulsória, tanto no âmbito da bioética como na sua efetividade, é preciso ampliar os estudos acerca desse tema tão escasso na literatura e, portanto, é objetivo desse trabalho.

\section{Resultados e Discussão}

Os defensores da internação compulsória alegam a eficácia de algumas estratégias da coerção. Entretanto, esse tipo de internação gera uma relutância do ponto de vista de alguns médicos, uma vez que há duas grandes preocupações: a autonomia do paciente (mesmo que ela já esteja comprometida devido ao abuso de álcool e substâncias) e a reduzidas evidências sobre esse tipo de intervenção ${ }^{(6)}$. Além disso, os resultados indicam que a efetividade do tratamento sob controles sociais e coerção é baixa. A fundamentação do desenvolvimento de políticas e de práticas de tratamento compulsório ou involuntário em massa é questionável, visto que, até o momento, as pesquisas sofrem limitações como o foco em argumentos não empíricos que denunciam ou defendem o uso de coerção. ${ }^{(7)}$

A metodologia utilizada foi a revisão narrativa de artigos publicados em inglês e português nas bases de dados: PUBMED e SciELO . Os artigos utilizados como referências visam responder à questão da efetividade da internação compulsória de usuários problemáticos de drogas.

\section{Conclusões}

Os problemas éticos abordados na questão do tratamento do usuário problemático de drogas apontam para riscos à autonomia do indivíduo ${ }^{(8)}$. Como a melhor prática clínica é uma questão não respondida, o estabelecimento de critérios para a internação compulsória deve ser um processo contínuo e discutido caso a caso, jamais como política de massa ${ }^{(7)}$. Além disso, a execução do tratamento decorrente de internação compulsória deve ser feita, segundo indica a lei, após o esgotamento de outras medidas que respeitem a autonomia do usuário, e baseadas no modelo de trabalho em equipe interdisciplinar que deve incluir avaliação psicológica, consulta médica e ações do Serviço Social, e pode incluir articulações com o Poder Judiciário de forma a reduzir os danos associados ao uso problemático de substâncias. ${ }^{(9)}$

\section{Agradecimentos}

Gostaria de agradecer ao CNPQ pela oportunidade e pelo apoio financeiro.

1. Coelho, I.; Oliveira, M. H. B. Saúde Debate 2014 v.38, n.101, pp. 359367

2. Sjostrand, M. Bioethics ISSN0269-9702 (print) 2008 v.22 pp. 113-120

3. Schramm, F. R.; Palácios M.; Rego, S. Ciên Saúde Coletiva 2008 v.13 n.2

4. The Authors, Addiction, 2013, 108, 650-651

5. Dalsenter, F. B., Revista Percurso 2012 v.12 n.1

6. Sullivan, M. A. The American Journal on Addictions 2008 17: 26-47

7. Kallert, T.W., Curr Opin Psychiatry 2008 21:485-489

8. Janssens M.J.P.;Van Rooij M.F.A.M.;tem Have,H.A.M.J.;Kortmann FAM, Van Wijmen F.C.B. J Med Ethics $200430453-458$

9. Werb,D.;Kamarulzaman,A.;Meacham,M.C.;Rafful,C.;Fischer,B Strathdee S. A. ;Wood E. International Journal of Drug Police 2016281 9 